\title{
Performance of an in-house real-time polymerase chain reaction for identification of Mycobacterium tuberculosis isolates in laboratory routine diagnosis from a high burden setting
}

\author{
Juliana Failde Gallo ${ }^{1}$, Juliana Maira Watanabe Pinhata ${ }^{1 /+}$, Erica Chimara ${ }^{1}$, \\ Maria Gisele Gonçalves², Lucila Okuyama Fukasawa², Rosangela Siqueira de Oliveira ${ }^{1}$
}

${ }^{1}$ Instituto Adolfo Lutz, Centro de Bacteriologia, Núcleo de Tuberculose e Micobacterioses, São Paulo, SP, Brasil

${ }^{2}$ Instituto Adolfo Lutz, Centro de Imunologia, Laboratório de Diagnóstico Molecular de Infecções Bacterianas, São Paulo, SP, Brasil

Brazil is one of the high burden countries for tuberculosis, and a rapid diagnosis is essential for effective control of the disease. In the present study, an in-house real-time polymerase chain reaction (PCR) assay targeting the mpt64 gene for identification of Mycobacterium tuberculosis complex isolates was evaluated under routine diagnosis conditions in a reference laboratory. From May 2011 to July 2012, 1,520 isolates of mycobacteria were prospectively submitted for phenotypic and/or PRA-hsp65 identification and to real-time PCR. The mpt64 real-time PCR showed $99.7 \%$ sensitivity and $96 \%$ specificity and detected $79.4 \%$ of the cases missed by phenotypic and PRAhsp65 identification. The in-house real-time PCR assay showed high sensitivity and specificity and was successfully implemented in the routine diagnosis of tuberculosis in a reference laboratory from a high burden setting.

Key words: molecular diagnostics - MPT64 protein - Mycobacterium tuberculosis -

real-time polymerase chain reaction - tuberculosis

In 2014, an estimated 9.6 million people developed tuberculosis (TB) worldwide, and 1.5 million people died from the disease (WHO 2015). Brazil is one of the 22 high TB burden countries, with more than 67,000 cases diagnosed in 2014, of which $23 \%$ were from the state of São Paulo (SP) (MS 2015).

Isolation of Mycobacterium tuberculosis complex (MTC) from clinical specimens is the gold standard for TB diagnosis. In pure culture, identification of mycobacteria can be performed by either phenotypic or molecular techniques (de Waard \& Robledo 2007). Phenotypic identification requires at least 15 days, whereas molecular diagnostics can be performed within hours (Espy et al. 2006, Pfyffer 2007).

Real-time polymerase chain reaction (PCR) has been used with high sensitivity and specificity for the rapid identification of MTC clinical isolates (Miller et al. 2002, Richardson et al. 2009, Hong et al. 2011). Several regions of the mycobacterial genome have been used as targets by molecular assays, e.g., IS6110, 16S rRNA, $h s p 65, r p o \mathrm{~B}, s d a \mathrm{~A}$, devR and mpt64 (Eisenach et al. 1990, Manjunath et al. 1991, Kadival et al. 1996, Lachnik et al. 2002, Kim et al. 2004, Chakravorty et al. 2005, Negi et al. 2007, Hwang et al. 2013, Nimesh et al. 2013).

The mpt64 gene (GenBank accession no. NC_000962) is found as a single copy exclusively in the genome of MTC species (Lee et al. 1994) and has been used for both pulmonary and extrapulmonary TB diagnosis (Tan

doi: 10.1590/0074-02760160048

+ Corresponding author: jupinhata@ial.sp.gov.br

Received 10 February 2016

Accepted 30 June 2016 et al. 1995, Martins et al. 2000, Takahashi \& Nakayama 2006, Pinhata et al. 2015). This gene has been reported to be very specific and sensitive when compared with other targets (Nimesh et al. 2013).

The Adolfo Lutz Institute (IAL) is a reference laboratory for TB in SP that has a well-established network composed of 291 local laboratories. Smear microscopy and culture are performed by these local laboratories, which then send the mycobacterial isolates to the IAL.

Nearly 7,000 isolates of mycobacteria from the local laboratories are received by the IAL annually. These isolates are routinely identified by conventional phenotypic techniques and PRA-hsp 65 , and/or submitted to phenotypic drug susceptibility testing (DST), an assay currently performed if the patient meets one of these following criteria: has a positive culture at the 2nd month of treatment, has had contact with multidrug-resistant $\mathrm{TB}$, is immunosuppressed, has a history of previous treatment or belongs to a vulnerable population (e.g., homeless, immigrant, indigenous, inpatient and prisoner populations) (MS 2011).

The GeneXpert MTB/RIF (Cepheid, Sunnyvale, USA), a commercially available molecular system that detects the MTC and resistance to rifampicin (RIF) directly from biological specimens, was implemented at 37 local laboratories in SP for nearly two years and is used only for the detection of new cases or in retreatment cases for resistance detection. However, as only 37 of the 291 local laboratories have implemented this system, the majority of the local laboratory network still uses smear microscopy and culture for TB diagnosis. Furthermore, the sensitivity of the GeneXpert assay is reduced for sputum samples with a low volume as well as for paucibacillary specimens, and culture remains the gold standard in such cases. 
In SP, most TB diagnoses still rely on culture, and the mycobacterial isolates have to be rapidly and accurately identified by the reference laboratory to promote effective TB control. Thus, the aim of this study was to evaluate the performance of an in-house real-time PCR assay targeting the mpt64 gene for rapid identification of MTC isolates under routine diagnosis conditions to incorporate this technique in a reference laboratory with a very high demand for exams.

\section{MATERIALS AND METHODS}

Optimization of the mpt64 real-time PCR assay - The limit of detection (LOD) of the real-time PCR assay was assessed before its implementation in the diagnosis routine. The primer and probe sequences for detection of the mpt64 gene were the same as described by Takahashi and Nakayama (2006), and the assay was performed as previously reported by these authors with modifications to the oligonucleotide concentrations used. Primer concentrations from 0.1 to $0.9 \mu \mathrm{M}$ and probe concentrations from 0.1 to $0.2 \mu \mathrm{M}$ were tested. The DNA from the $\mathrm{H} 37 \mathrm{Rv}$ isolate of MTC (ATCC 27294) was extracted and purified with a Genomic DNA from Tissue kit (Macherey-Nagel, Düren, Germany) and diluted in ultra-pure water to a concentration of $10 \mathrm{ng} / \mu \mathrm{L}$. The LOD was obtained by amplification of 10 -fold dilutions of this purified DNA from $10 \mathrm{ng} / \mu \mathrm{L}$ to $1 \mathrm{fg} / \mu \mathrm{L}$. DNA concentrations were measured with a spectrophotometer. The LOD was determined to be the dilution that yielded a cycle quantification $(\mathrm{Cq})$ value of 31 .

After determination of the LOD, the molecular assay was evaluated using 268 isolates of 29 Mycobacterium species and 274 isolates of 36 non-Mycobacterium species (Table I). The assays were performed in a final reaction volume of $25 \mu \mathrm{L}$ and were performed using TaqMan ${ }^{\circledR}$ Universal Master Mix (Applied Biosystems, Foster City, CA) with $2 \mu \mathrm{L}$ of the isolates' DNA. Forward primer, reverse primer and probe for mpt64 were used in concentrations of $0.3,0.3$ and $0.1 \mu \mathrm{M}$. All of the isolates were tested in duplicate, and in each reaction, two wells for the positive control (H37Rv) and four wells for negative controls without DNA (two for the Master Mix preparation step and two for the DNA addition step) were included. The reactions were performed using the Roche LightCycler 480 II system (Roche Diagnostics, Indianapolis, USA) with the following cycling parameters: $50^{\circ} \mathrm{C}$ for $2 \mathrm{~min}$ and $95^{\circ} \mathrm{C}$ for $10 \mathrm{~min}$ followed by 40 cycles of $95^{\circ} \mathrm{C}$ for $15 \mathrm{~s}$ and $60^{\circ} \mathrm{C}$ for $1 \mathrm{~min}$. Positive results were defined as $\mathrm{Cq}$ values $\leq 31$, according to the LOD of the mpt64 gene. All of the inconclusive results and inconsistent replicates were repeated. When repeated assays again resulted in inconclusive results, the isolate was sent for phenotypic and PRA-hsp 65 identification.

Implementation of the mpt64 real-time PCR assay in the TB diagnosis routine - From May 2011 to July 2012, 1,520 primary isolates of mycobacteria in liquid or on solid media from SP, Brazil, were included in the study. First, a presumptive identification according to micro- and macroscopic characteristics of the isolates was performed to classify these samples as MTC or non- tuberculous mycobacteria (NTM) isolates as described elsewhere (Monteiro et al. 2003, Coelho et al. 2007, Simeão et al. 2009) (Figure).

Next, mpt64 real-time PCR was performed in the following cases: (i) isolates presumptively identified as MTC without DST criteria; and (ii) isolates that underwent DST but exhibited growth on PNB and BHI agar suggestive of contamination by other bacteria/fungi (Figure).

Phenotypic and PRA- $h s p 65$ identification was performed when (i) isolates underwent DST but exhibited growth only on PNB or growth on PNB and on BHI agar suggestive of NTM; or (ii) isolates were presumptively identified as NTM (these were not included in the study) (Figure).

Phenotypic tests included growth rate (fast or slow), growth in temperatures of $26^{\circ} \mathrm{C}$ and $37^{\circ} \mathrm{C}$, observation of colony pigmentation, and growth in the presence of 500 $\mu \mathrm{g} / \mathrm{mL}$ of p-nitrobenzoic acid (PNB), sodium nitrite and picric acid (MS 2008). The first reading was performed after one week of incubation, and the isolates that showed no growth were incubated for one more week. PRA-hsp 65 identification was performed as described by Chimara et al. (2008).

For real-time PCR DNA extraction, lysates of mycobacteria were prepared as follows: for isolates on solid media, a loop-full of organisms was suspended in $500 \mu \mathrm{L}$ of ultra-pure water; for isolates in liquid media, $500 \mu \mathrm{L}$ of bacterial growth was transferred to a sterile screw-capped tube. The suspensions were boiled at $100^{\circ} \mathrm{C}$ for $20 \mathrm{~min}$ and frozen at $-20^{\circ} \mathrm{C}$ for at least $18 \mathrm{~h}$ (Chimara et al. 2008).

Real-time PCR was performed as described above. Isolates with $\mathrm{Cq}$ values from 14-31 were considered positive for mpt64; Cq values of 0 or $\geq 40$ indicated that the isolate was negative; and $\mathrm{Cq}$ values from 32-39 were considered inconclusive results.

Analysis of results - Sensitivity, specificity, positive predictive value (PPV), negative predictive value (NPV), and accuracy of the mpt64 real-time PCR assay were calculated under $95 \%$ confidence intervals (CI) using Microsoft Excel 2003 (Drobatz 2009). This work was approved by the Scientific Technical Committee of the Adolfo Lutz Institute, São Paulo, Brazil (19797/2009). Ethical approval was not required, as only mycobacterial isolates were analysed.

\section{RESULTS}

The mpt64 real-time PCR assay showed an efficiency of $94.69 \%$ (slope $=-3.456$, coefficient of correlation $=0.944$ ) and an LOD of 20 fg of MTC genomic DNA. All of the 127 MTC isolates used in the evaluation of this assay before its implementation in the TB diagnosis routine were positive for mpt64. All of the isolates from other mycobacterial species and other genera yielded negative results (Table I).

Among the 1,520 mycobacterial isolates analysed prospectively, 1,352 (88.9\%) were identified as MTC by presumptive features or phenotypic techniques and PRA- $h s p 65$, including contaminated and mixed cultures. The real-time PCR assay identified MTC in 1,384 $(91 \%)$ of isolates analysed (Table II). 
There were 13 isolates identified as a mixture of MTC and NTM, all of which were positive for mpt64. Regarding six of these mixed cultures, PRA-hsp65 analysis identified the species as follows: two isolates as MTC $+M$. intracellulare; two isolates as $\mathrm{MTC}+M$. avium; one isolate as MTC $+M$. kansasii; and one isolate as MTC $+M$. abscessus subsp. abscessus. The remaining seven isolates did not amplify on PRA-hsp65 and the phenotypic tests could not identify the NTM species.

Three of the four NTM isolates that were positive for mpt64 were identified by the PRA-hsp 65 assay as M. chelonae, M. kansasii and M. avium/M. colombiense. The remaining NTM isolate did not amplify on PRA and the phenotypic tests revealed that this sample was an achromogen rapid grower mycobacterium.

Fifty-five (3.6\%) of the isolates that could not be identified by the conventional techniques (contamination or no growth/amplification on PRA-hsp65) had valid real-time PCR results and corresponded to 55 different patients. To evaluate the performance of the real-time PCR for the mpt64 gene for these isolates, we accessed the TB Notification System (TB-WEB) of the Center of Epidemiological Surveillance of SP. If the patient's TB status was annotated in the system, the sample was con- sidered to be from a confirmed TB case. Among these 55 isolates without identification results, there were 34 confirmed TB cases, of which 27 (79.4\%) were detected by the real-time PCR assay. Of the 21 non-TB cases, real-time PCR results were negative in $16(76.2 \%)$.

Isolates with inconclusive real-time PCR results and isolates that presented contamination or no growth/amplification on PRA- $h s p 65(\mathrm{n}=69)$ were excluded from the analysis of sensitivity and specificity of the real-time PCR assay. Of the 1,451 isolates included in this analysis, $1,351(93.2 \%)$ were identified as MTC by phenotypic tests and/or PRA-hsp65. Real-time PCR results were positive for MTC in 1,347 of these isolates (sensitivity of 99.7\%). Among the $100(6.8 \%)$ isolates that were negative for MTC by the culture assay, 96 were also negative in real-time PCR assay ( $96 \%$ of specificity) (Table III).

\section{DISCUSSION}

Rapid identification of mycobacterial clinical isolates is essential for TB control and management of TB cases. The Adolfo Lutz Institute must be able to provide results in a short period of time because it is the reference laboratory for the state of São Paulo that diagnoses the majority of TB cases every year in Brazil.

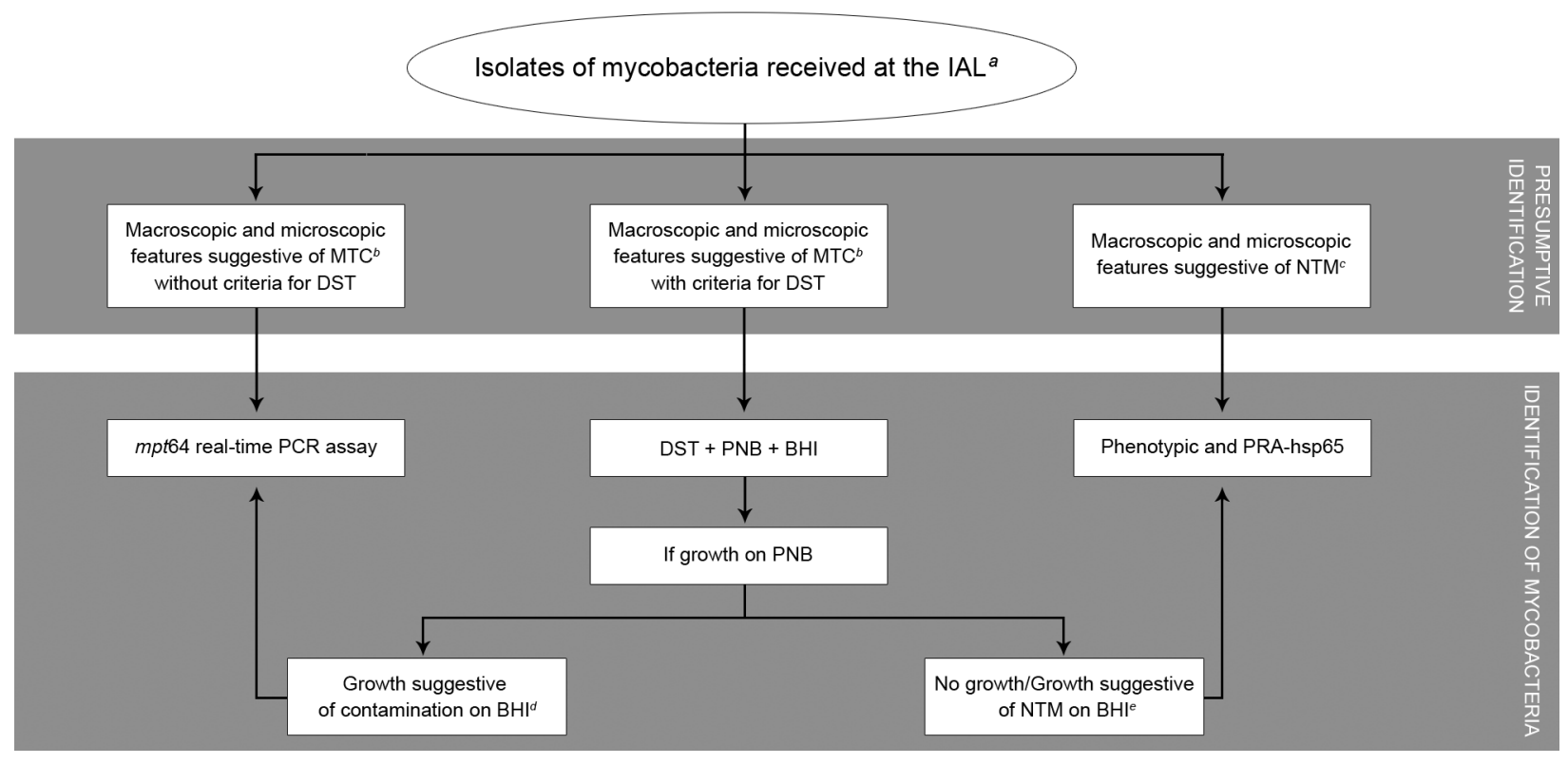

Scheme of the tuberculosis diagnosis routine at the Adolfo Lutz Institute (IAL), a reference laboratory for tuberculosis and mycobacteriosis diagnosis in the state of São Paulo, Brazil. DST: drug susceptibility testing; PNB: p-nitrobenzoic acid; BHI: brain-heart infusion agar; $a$ : IAL receives only cultures, not biological samples; $b$ : Mycobacterium tuberculosis complex (MTC) presumptive identification included: rough and non-chromogenic colonies on solid media or flocculated growth in the liquid medium (macroscopic features) and presence of cord factor (microscopic features); $c$ : non-tuberculous mycobacteria (NTM) presumptive identification included: rough/smooth and chromogenic/non-chromogenic colonies on solid media or non-flocculated growth in the liquid medium (macroscopic features) and absence of cord factor (microscopic features); $d$ : for isolates that exhibited growth in the presence of $500 \mu \mathrm{g} / \mathrm{mL}$ of PNB and growth suggestive of contamination on BHI, the real-time polymerase chain reaction assay was performed for the primary isolate that arrived at the IAL; $e$ : for isolates that exhibited growth in the presence of $500 \mu \mathrm{g} / \mathrm{mL}$ of PNB and no growth or growth suggestive of NTM on BHI, phenotypic assays and PRA-hsp65 identification were performed for the primary isolate and the isolate that grew on PNB. 
This is the first study that uses mpt64 as a target to identify MTC primary clinical isolates. Detection of the mpt64 gene was $100 \%$ sensitive and specific for MTC when real-time PCR was tested against previously identified mycobacterial and non-mycobacterial species. Under routine conditions, this assay also showed high sensitivity and specificity in the detection of MTC, as found by other authors (Gonçalves et al. 2012, Pinhata et al. 2015). Gonçalves et al. (2012) obtained high sensitivity and specificity using molecular beacons in an in-house real-time PCR assay to detect resistance to isoniazid and RIF in 988 MTC primary isolates received at the IAL. In

TABLE I

Results of mpt64 real-time polymerase chain reaction for 268 Mycobacterium sp. isolates and 274 non-Mycobacterium isolates tested

\begin{tabular}{|c|c|c|}
\hline Organism & $\begin{array}{l}\text { Strains } \\
\left(\mathrm{n}^{\mathrm{o}}\right)\end{array}$ & $\begin{array}{l}\text { Strains positive } \\
\text { for mpt64 } \\
\qquad\left(\mathrm{n}^{\mathrm{o}}\right)\end{array}$ \\
\hline Mycobacterium tuberculosis & 124 & 124 \\
\hline M. bovis & 3 & 3 \\
\hline Total & 127 & 127 \\
\hline M. abscessus & 11 & 0 \\
\hline M. asiaticum & 1 & 0 \\
\hline M. avium & 22 & 0 \\
\hline M. bohemicum & 1 & 0 \\
\hline M. bolletti & 1 & 0 \\
\hline M. brumae & 1 & 0 \\
\hline M. celatum & 1 & 0 \\
\hline M. chelonae & 3 & 0 \\
\hline M. flavescens & 2 & 0 \\
\hline M. fortuitum & 11 & 0 \\
\hline M. gordonae & 23 & 0 \\
\hline M. immunogenum & 1 & 0 \\
\hline M. intracellulare & 17 & 0 \\
\hline M. kansasii & 19 & 0 \\
\hline M. lentiflavum & 4 & 0 \\
\hline M. mисоgenicum & 3 & 0 \\
\hline M. nonchromogenicum & 1 & 0 \\
\hline M. parascrofulaceum & 1 & 0 \\
\hline M. peregrinum & 8 & 0 \\
\hline M. phocaicum & 1 & 0 \\
\hline M. rhodesiae & 1 & 0 \\
\hline M. scrofulaceum & 2 & 0 \\
\hline M. simiae & 1 & 0 \\
\hline M. smegmatis & 1 & 0 \\
\hline M. szulgai & 1 & 0 \\
\hline M. terrae & 1 & 0 \\
\hline M. triviale & 1 & 0 \\
\hline M.xenopi & 1 & 0 \\
\hline Total & 141 & 0 \\
\hline
\end{tabular}

this study, we decided to design a real-time PCR assay to identify MTC isolates in our TB diagnosis routine.

Pinhata et al. (2015) evaluated the performance of the mpt64 real-time PCR assay directly in sputum samples and obtained the same sensitivity as that of culture $(90.3 \%)$, as well as a specificity of $98.6 \%$. Our study showed values of sensitivity and specificity of the real-time PCR assay above $96 \%$. Moreover, this assay enabled the identification of MTC isolates in up to 48 hours, a substantial improvement in comparison to phenotypic methods, as phenotypic assays take at least two weeks to yield results.

\begin{tabular}{|c|c|c|}
\hline Organism & $\begin{array}{c}\text { Strains } \\
\left(n^{\circ}\right)\end{array}$ & $\begin{array}{l}\text { Strains positive } \\
\text { for } m p t 64 \\
\left(\mathrm{n}^{\circ}\right)\end{array}$ \\
\hline Acinetobacter baumannii & 1 & 0 \\
\hline Corynebacterium diphtheriae & 2 & 0 \\
\hline C. ulcerans & 1 & 0 \\
\hline Chlamydia pneumoniae & 1 & 0 \\
\hline C. trachomatis & 1 & 0 \\
\hline Coccidioides immitis & 1 & 0 \\
\hline Cryptococcus sp & 1 & 0 \\
\hline Enterobacter cloacae & 1 & 0 \\
\hline Escherichia coli & 5 & 0 \\
\hline Enterococcus faecalis & 2 & 0 \\
\hline Haemophilus aegyptius & 1 & 0 \\
\hline H. influenzae & 54 & 0 \\
\hline H. parainfluenzae & 3 & 0 \\
\hline Histoplasma capsulatum & 1 & 0 \\
\hline Klebsiella pneumoniae & 1 & 0 \\
\hline Listeria monocytogenes & 17 & 0 \\
\hline Legionella $s p$ & 1 & 0 \\
\hline Moraxella catarrhalis & 3 & 0 \\
\hline M. genitalium & 1 & 0 \\
\hline Neisseria lactamica & 2 & 0 \\
\hline N. meningitidis & 55 & 0 \\
\hline N. sicca & 2 & 0 \\
\hline N. subflava flava & 1 & 0 \\
\hline N. subflava perflava & 1 & 0 \\
\hline Nocardia asteroides & 1 & 0 \\
\hline Paracoccidioides brasiliensis & 1 & 0 \\
\hline Pneumocystis carinii & 1 & 0 \\
\hline Pseudomonas aeruginosa & 3 & 0 \\
\hline Salmonella Brandenburg & 1 & 0 \\
\hline$S$. Enteritidis & 1 & 0 \\
\hline$S$. Typhimurium & 1 & 0 \\
\hline Streptococcus agalactiae & 1 & 0 \\
\hline S. mitis & 1 & 0 \\
\hline S. pneumoniae & 67 & 0 \\
\hline S. pyogenes & 1 & 0 \\
\hline S. viridans & 36 & 0 \\
\hline Total & 274 & 0 \\
\hline
\end{tabular}


TABLE II

Results of identification and mpt64 real-time polymerase chain reaction (PCR) for the 1,520 mycobacterial isolates analysed

\begin{tabular}{|c|c|c|c|c|c|c|c|}
\hline \multirow[b]{2}{*}{ Real-time PCR } & \multicolumn{6}{|c|}{ Presumptive or phenotypic and PRA- $h s p 65$ identification } & \multirow[b]{2}{*}{ Total } \\
\hline & MTC & $\mathrm{MTC}+\mathrm{NTM}$ & $\mathrm{MTC}+\mathrm{CO}$ & NTM & $\mathrm{CO}$ & NG/NA & \\
\hline Positive & 1,332 & 13 & 2 & 4 & 21 & 12 & 1,384 \\
\hline Negative & 4 & 0 & 0 & 96 & 17 & 5 & 122 \\
\hline Inconclusive & 1 & 0 & 0 & 6 & 5 & 2 & 14 \\
\hline Total & 1,337 & 13 & 2 & 106 & 43 & 19 & 1,520 \\
\hline
\end{tabular}

CO: contamination; MTC: Mycobacterium tuberculosis complex; NG/NA: no growth and no amplification on PRA-hsp65 identification; NTM: non-tuberculous mycobacteria.

TABLE III

Performance of the mpt64 real-time polymerase chain reaction (PCR) assay based on valid culture identification results

\begin{tabular}{|c|c|c|c|c|c|c|c|c|}
\hline \multirow[b]{2}{*}{ Real-time PCR } & \multicolumn{3}{|c|}{ Culture $(\mathrm{n}=1,451)$} & \multirow{2}{*}{$\begin{array}{l}\text { Sensitivity } \\
(95 \% \mathrm{CI})\end{array}$} & \multirow{2}{*}{$\begin{array}{l}\text { Specificity } \\
(95 \% \text { CI })\end{array}$} & \multirow{2}{*}{$\begin{array}{c}\text { PPV } \\
(95 \% \text { CI })\end{array}$} & \multirow{2}{*}{$\begin{array}{c}\text { NPV } \\
(95 \% \mathrm{CI})\end{array}$} & \multirow[b]{2}{*}{ Accuracy } \\
\hline & Positive & Negative & Total & & & & & \\
\hline Positive & 1,347 & $4^{*}$ & 1,351 & $99.7 \%$ & $96 \%$ & $99.7 \%$ & $96 \%$ & $99.4 \%$ \\
\hline Negative & 4 & 96 & 100 & (99.2-99.9) & (90.1-98.9) & (99.2-99.9) & (90.1-98.9) & \\
\hline
\end{tabular}

NPV: negative predictive value; PPV: positive predictive value; *: all were NTM isolates: one Mycobacterium avium/intracellulare, one $M$. kansasii, one M. chelonae and one achromogen rapid grower.

In our TB diagnosis routine, results of identification by PRA- $h s p 65$ are available in approximately four days, twice as long compared with real-time PCR. Furthermore, real-time PCR enables the parallel testing of 45 isolates at once, whereas in PRA-hsp 65 identification, a maximum of 13 isolates can be included in an electrophoresis gel after enzymatic digestion. In PRA- $h s p 65$ identification, a visual analysis of restriction profiles must be performed after the gel is run, whereas the realtime PCR system gives results that are already analysed.

Another great advantage of real-time PCR is that this assay detected $27 / 34(79.4 \%)$ confirmed TB cases that were missed by phenotypic and PRA- $h \operatorname{sp} 65$ assay, allowing laboratory confirmation of TB.

The only inconclusive isolate in real-time PCR that was culture positive for MTC showed a Cq value of 33, a value very close to the LOD for the mpt64 gene $(\mathrm{Cq}=31)$, indicating that the amount of DNA in this culture was less than $20 \mathrm{fg}$. As this sample was a liquid culture, there could have been a very low quantity of bacilli, as the MGIT system is very sensitive in the detection of growth.

Four isolates positive for mpt64 in the real-time PCR assay were identified as NTM. According to the TBWEB system, two of these patients were being treated for TB at the study date because they presented clinical signs and symptoms, and both were cured. Between the other two patients with NTM, one had been previously treated for TB, whereas there is no annotated data regarding the other patient in the system. Presumably, cul- tures of these four patients were mixed MTC and NTM. However, as NTM grow faster, the amount of DNA isolated from these organisms was much higher for NTM than for MTC, and PRA-hsp65 identification detected only the NTM species. This can be explained by the fact that $h s p 65$, used as a target on PRA identification, is encountered in all Mycobacterium species, whereas mpt64 is specific for MTC.

In conclusion, this study demonstrates that the mpt64 real-time PCR assay can be routinely used for rapid and accurate identification of MTC isolates from patients with no criteria for DST or in cases of mixed and contaminated cultures in laboratories with a high burden of cases and provided with infrastructure and personnel trained in molecular techniques.

\section{REFERENCES}

Chakravorty S, Sen MK, Tyagi JS. Diagnosis of extrapulmonary tuberculosis by smear, culture, and PCR using universal sample processing technology. J Clin Microbiol. 2005; 43(9): 4357-62.

Chimara E, Ferrazoli L, Ueky SYM, Martins MC, Durham AM, Arbeit RD, et al. Reliable identification of mycobacterial species by PCR-restriction enzyme analysis (PRA)-hsp65 in a reference laboratory and elaboration of a sequence-based extended algorithm of PRA-hsp65 patterns. BMC Microbiol. 2008; 8: 48.

Coelho AGV, Zamarioli LA, Reis CMPV, Duca BFL. Detection of cord factor for the presumptive identification of Mycobacterium tuberculosis complex. J Bras Pneumol. 2007; 33(6): 707-11.

de Waard JH, Robledo J. Conventional diagnostic methods. In: Palo- 
mino JC, Leão SC, Ritacco V, editors. Tuberculosis 2007. From basic science to patient care. TuberculosisTextBook.com; 2007. p. $401-424$.

Drobatz KJ. Measures of accuracy and performance of diagnostic tests. J Vet Cardiol. 2009; 11(Suppl. 1): S33-40.

Eisenach KD, Cave MD, Bates JH, Crawford JT. Polymerase chain reaction amplification of a repetitive DNA sequence specific for Mycobacterium tuberculosis. J Infect Dis. 1990; 161(5): 977-81.

Espy MJ, Uhl JR, Sloan LM, Buckwalter SP, Jones MF, Vetter EA, et al. Real-time PCR in clinical microbiology: applications for routine laboratory testing. Clin Microbiol Rev. 2006; 19(1): 165-256.

Gonçalves MG, Fukasawa LO, Oliveira RS, Salgado MM, Harrison $\mathrm{LH}$, Shutt KA, et al. Fast test for assessing the susceptibility of Mycobacterium tuberculosis to isoniazid and rifampin by realtime PCR. Mem Inst Oswaldo Cruz. 2012; 107(7): 903-8.

Hong YJ, Chung YH, Kim TS, Song SH, Park KU, Yim JJ, et al. Usefulness of three-channel multiplex real-time PCR and melting curve analysis for simultaneous detection and identification of the Mycobacterium tuberculosis complex and nontuberculous mycobacteria. J Clin Microbiol. 2011; 49(11): 3963-6.

Hwang SM, Lim MS, Hong YJ, Kim TS, Park KU, Song J, et al. Simultaneous detection of Mycobacterium tuberculosis complex and nontuberculous mycobacteria in respiratory specimens. Tuberculosis. 2013; 93(6): 642-6.

Kadival GV, D’Souza CD, Kulkarni SP, Samuel AM. A highly specific polymerase chain reaction for detection of Mycobacterium tuberculosis. Indian J Tuberculosis. 1996; 43(3): 151-4.

Kim BJ, Hong SK, Lee KH, Yun YJ, Kim EC, Park YG, et al. Differential identification of Mycobacterium tuberculosis complex and nontuberculous mycobacteria by duplex PCR assay using the RNA polymerase gene (rpoB). J Clin Microbiol. 2004; 42(3): 1308-12.

Lachnik J, Ackermann B, Bohrssen A, Maass S, Diephaus C, Puncken A, et al. Rapidcycle PCR and fluorimetry for detection of mycobacteria. J Clin Microbiol. 2002; 40(9): 3364-73.

Lee BW, Tan JA, Wong SC, Tan CB, Yap HK, Low PS, et al. DNA amplification by the polymerase chain reaction for the rapid diagnosis of tuberculous meningitis. Comparison of protocols involving three mycobacterial DNA sequences, IS6110, $65 \mathrm{kDa}$ antigen, and MPB64. J Neurol Sci. 1994; 123(1-2): 173-9.

Manjunath N, Shankar P, Rajan L, Bhargava A, Saluja S, Shriniwas. Evaluation of a polymerase chain reaction for the diagnosis of tuberculosis. Tubercle. 1991; 72(1): 21-7.

Martins LC, Paschoal IA, Von Nowakonski A, Silva SAB, Costa FF, Ward LS. Nested-PCR using MPB64 fragment improves the diagnosis of pleural and meningeal tuberculosis. Rev Soc Bras Med Trop. 2000; 33(3): 253-7.

Miller N, Cleary T, Kraus G, Young AK, Spruill G, Hnatyszyn HJ. Rapid and specific detection of Mycobacterium tuberculosis from acid-fast bacillus smear-positive respiratory specimens and BacT/ALERT MP culture bottles by using fluorogenic probes and real-time PCR. J Clin Microbiol. 2002; 40(11): 4143-7.

Monteiro PHT, Martins MC, Ueki SYM, Giampaglia CMS, Telles MAS. Cord formation and colony morphology for the presump- tive identification of Mycobacterium tuberculosis complex. Braz J Microbiol. 2003; 34(2): 171-4.

MS - Ministério da Saúde. Detectar, tratar e curar: desafios e estratégias brasileiras frente à tuberculose. Boletim Epidemiológico. 2015. Available from: http://u.saude.gov.br/images/pdf/2015/ marco/25/Boletim-tuberculose-2015.pdf.

MS - Ministério da Saúde. Manual de recomendações para o controle da tuberculose no Brasil. 2011. Available from: http:// www.cve.saude.sp.gov.br/htm/TB/mat_tec/manuais/MS11_ Manual_Recom.pdf.

MS - Ministério da Saúde. Manual nacional de vigilância laboratorial da tuberculose e outras micobactérias. 2008. Available from: http://bvsms.saude.gov.br/bvs/publicacoes/manual_vigilancia laboratorial_tuberculose.pdf.

Negi SS, Anand R, Pasha ST, Gupta S, Basir SF, Khare S, et al. Diagnostic potential of IS6110, $38 \mathrm{kDa}, 65 \mathrm{kDa}$ and $85 \mathrm{~B}$ sequencebased polymerase chain reaction in the diagnosis of Mycobacterium tuberculosis in clinical samples. Indian J Med Microbiol. 2007; 25(1): 43-9.

Nimesh M, Joon D, Pathak AK, Saluja D. Comparative study of diagnostic accuracy of established PCR assays and in-house developed sdaA PCR method for detection of Mycobacterium tuberculosis in symptomatic patients with pulmonary tuberculosis. $\mathrm{J}$ Infect. 2013; 67(5): 399-407.

Pfyffer GE. Mycobacterium: general characteristics, laboratory detection, and staining procedures. In: Murray PR, Baron EJ, Jorgensen JH, Landry ML, Pfaller MA, editors. Manual of clinical microbiology. Washington (DC): ASM Press; 2007. p. 543-72.

Pinhata JMW, Cergole-Novella MC, Carmo MAS, Ferro e Silva RR, Ferrazoli L, Sacchi CT, et al. Rapid detection of Mycobacterium tuberculosis complex by real-time PCR in sputum samples and its use in the routine diagnosis in a reference laboratory. J Med Microbiol. 2015; 64(9): 1040-5.

Richardson ET, Samson D, Banaei N. Rapid identification of Mycobacterium tuberculosis and nontuberculous mycobacteria by multiplex, real-time PCR. J Clin Microbiol. 2009; 47(5): 1497-502.

Simeão FCS, Chimara E, Oliveira RS, Yamauchi JU, Latrilha FO, Telles MAS. Cord factor detection and macroscopic evaluation of mycobacterial colonies: an efficient combined screening test for the presumptive identification of Mycobacterium tuberculosis complex on solid media. J Bras Pneumol. 2009; 35(12): 1212-6.

Takahashi T, Nakayama T. Novel technique of quantitative nested real-time PCR assay for Mycobacterium tuberculosis DNA. J Clin Microbiol. 2006; 44(3): 1029-39.

Tan J, Lee BW, Lim TK, Chin NK, Tan CB, Xia JR, et al. Detection of Mycobacterium tuberculosis in sputum, pleural and bronchoalveolar lavage fluid using DNA amplification of the MPB 64 protein coding gene and IS6110 insertion element. Southeast Asian J Trop Med Public Health. 1995; 26(2): 247-52.

WHO - World Health Organization. Global tuberculosis report 2015. 2015. Available from: http://apps.who.int/iris/bitstre am/10665/191102/1/9789241565059_eng.pdf. 